\title{
Posttraumatic Guillain-Barré Syndrome Immediately Following a Traffic Accident
}

\section{Jungook Kim, \\ Ho Yong Choi, \\ Young Min Lee, Joon Soo Kim}

\section{Department of Neurosurgery, Samsung Changwon Hospital, Sungkyunkwan University School of Medicine, Changwon, Korea \\ Corresponding Author: \\ Ho Yong Choi \\ Department of Neurosurgery, Samsung Changwon Hospital, Sungkyunkwan University School of Medicine, 158 Paryong-ro, Masanhoewon-gu, Changwon 51353, Korea}

Tel: +82-55-233-5896

Fax: +82-55-233-5269

E-mail: heoryong83@hanmail.net

Received: August 21, 2017 Revised: September 3, 2017 Accepted: September 5, 2017
Copyright (C) 2017 by The Korean Spinal Neurosurgery Society

This is an open access article distributed under the terms of the Creative Commons Attribution Non-Commercial License (http://creativecommons.org/licenses/bync/4.0/) which permits unrestricted noncommercial use, distribution, and reproduction in any medium, provided the original work is properly cited.

Guillain-Barré syndrome (GBS) is an inflammatory demyelinating polyneuropathy characterized by areflexic paralysis. Most cases of GBS are preceded by an infection, however, posttraumatic GBS has also recently been reported. We report a case of posttraumatic GBS immediately following a traffic accident. We think this case is of clinical significance for practitioners because of the rare cause of a sudden flaccid paralysis following trauma.

Key Words: Posttraumatic GBS, Guillain-Barré syndrome, Trauma

\section{INTRODUCTION}

Guillain-Barré syndrome (GBS) is an inflammatory demyelinating polyneuropathy characterized by areflexic paralysis that is not commonly encountered in the neurosurgical field ${ }^{5,19)}$. Most cases of GBS are preceded by an infection, such as an upper respiratory infection or enteritis. However, posttraumatic GBS has also recently been reported ${ }^{3,4,9,16}$.

Here, we report a case of abrupt paralysis of the lower extremities immediately following a traffic accident. The patient was confirmed as having GBS with an electromyogram/nerve conduction study (EMG/NCS) and cerebrospinal fluid (CSF) assessment, and was successfully treated with administration of intravenous immunoglobulin (IVIG).

To our knowledge, this is a unique case of posttraumatic GBS in which the symptom onset was immediately after the trauma. We think that this case is of clinical significance for practitioners because of the rare cause of a sudden flaccid paralysis following trauma.

\section{CASE REPORT}

A 36-year-old previously healthy man presented with abrupt flaccid paralysis of the lower limbs immediately following a traffic accident. Examination showed profound weakness of both legs (grade 1) combined with severe lancinating paresthesia at the posterior surface of the right leg. His left leg weakness spontaneously improved to grade IV within a few hours after injury. Deep tendon reflexes were absent. Bladder dysfunction was noted and catheterization was required. Pathologic reflexes, such as Babinski sign and ankle clonus, were absent.
To treat apparent spinal cord injury or cauda equina syndrome, the patient was administered a high-dose steroid. However, a few days later, the patient complained of mild weakness and tremor in both upper extremities without improvement of right leg weakness.

Whole spine magnetic resonance imaging (MRI) demonstrated mild central intervertebral disc herniation at L5/S1 that was of little clinical significance (Fig. 1). Otherwise, there was no significant pathology, including compressive lesion, cord contusion, or hemorrhage. Brain MRI also showed no significant abnormality. EMG/NCS was conducted 7 days after the accident, which did not demonstrate any abnormal findings. However, 3 weeks after the accident, a follow-up EMG/NCS was conducted. In the motor NCS, terminal latency was increased and conduction velocity was decreased in both upper and lower extremities. Sensory NCS showed decreased conduction velocity in both upper and lower extremities. There was increased F-wave latency in all 4 extremities. The assessment showed signs of demyelinating sensorimotor polyneuropathy. Furthermore, CSF assessment showed a mild elevation of protein levels, consistent with inflammatory demyelinating polyneuropathy and leading to a final diagnosis of GBS. The patient was transferred to the department of neurology, where he was treated with administration of IVIG.

Three months after the accident, symptoms showed gradual improvement and the patient could walk stably with a cane. Bladder dysfunction had also improved. At the final follow-up, 5 months after the accident, the patient's condition was stable. Further EMG/NCS still showed demyelinating sensorimotor polyneuropathy without significant changes since previous assessments. 


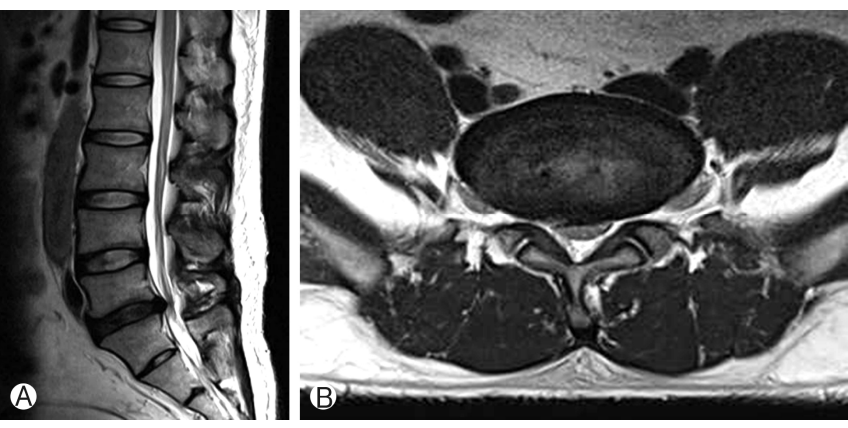

Fig. 1. Lumbar spine magnetic resonance imaging (MRI) demonstrated herniated intervertebral disc at L5/S1 level in sagittal and axial images, respectively (A and B). Muscle weakness of the lower extremities of the patient could not be explained by MRI findings.

\section{DISCUSSION}

In the present case, we report a case of posttraumatic GBS. We believe the case is of particular importance for clinicians for several reasons. First, to the best of our knowledge, this is the first reported case of GBS that developed immediately following a traffic accident. Second, such a case of sudden paralysis of the lower extremities after traffic accident without significant disc herniation or compressive lesion upon cauda equina may be difficult to diagnose, leading to confusion and embarrassment for both doctors and patients. Finally, such cases might result in disputes for insurance compensation, since the relationship between GBS and trauma has not been well established.

GBS is an inflammatory demyelinating polyradiculopathy, characterized by acute areflexic paralysis and demyelinating changes in the peripheral nervous system. The majority of cases are preceded by upper respiratory infection or diarrhea, with the most frequently identified infectious agent being Campylobacter jejuni, followed by cytomegalovirus ${ }^{6,8,10}$. The main feature of GBS is progressive bilateral and relatively symmetric weakness of the limbs, with the weakness progressing over a period of 12 hours to 28 days before a plateau is reached ${ }^{15}$. Electrophysiologic study can confirm the presence and classification of $\mathrm{GBS}^{20)}$. The typical finding from a lumbar puncture is albuminocytologic dissociation $^{20)}$.

In contrast to well-established infectious etiology, the concept of posttraumatic GBS preceded by no risk factors other than trauma has been recently introduced. There have already been several reports of posttraumatic GBS, following physical damage from traffic accidents, falling, or surgery ${ }^{1,7,11-14,17,18)}$. However, in all previous cases, the time from trauma to symptom onset was more than several days. The main difference of the present case from those previously reported is the immediate onset of flaccid weakness following trauma, which could lead to suspicions of mechanical compressive lesions rather than an inflammatory process.

The main pathological pathway for GBS is a triggered immune-mediated response resulting in multifocal mononuclear cell infiltration throughout the peripheral nervous system ${ }^{2)}$. In the case of posttraumatic GBS, it is postulated that the underlying mechanisms are based on a trauma-related disruption of the cellular and humoral immune system ${ }^{11)}$. In the present case, however, it is difficult to understand how such immune-mediated reactions happened so promptly following trauma, and the possible mechanism is yet to be explained.

Because of the rarity of posttraumatic GBS and the lack of systematic research, the role of immunological treatment has not yet been established. However, there exist some studies reporting the value of an empiric course of IVIG or plasma exchange ${ }^{7,14,177}$. In the present case, the patient showed considerable recovery with IVIG without relapse for 6 months. Similar to the treatment for other cases of GBS, immunotherapy with IVIG or plasma exchange may be viable options for the management of posttraumatic GBS.

Posttraumatic GBS is a rapidly progressive disorder, resulting in severe neurological complications. Clinicians should take into account the possibility of posttraumatic GBS in cases of unexplained muscle weakness after trauma, because appropriate corresponding measures including general medical care and immunotherapy could relieve and improve the condition.

\section{CONCLUSION}

Posttraumatic GBS can occur immediately after a trauma, such as a traffic accident. This rare condition can be successfully treated with immunotherapy, and should be considered in unexplained paralytic patients without significant radiologic abnormalities following trauma.

\section{CONFLICT OF INTEREST}

No potential conflict of interest relevant to this article was reported.

\section{REFERENCES}

1. Al-Hashel JY, John JK, Vembu P: Unusual presentation of GuillainBarré syndrome following traumatic bone injuries: report of two cases. Med Princ Pract 22:597-599, 2013

2. Asbury AK, Arnason BG, Adams RD: The inflammatory lesion in idiopathic polyneuritis. Its role in pathogenesis. Medicine (Baltimore) 48:173-215, 1969

3. Carr KR, Shah M, Garvin R, Shakir A, Jackson C: Post-traumatic brain injury (TBI) presenting with Guillain-Barré syndrome and elevated anti-ganglioside antibodies: a case report and review of the literature. Int J Neurosci 125:486-492, 2015

4. Gensicke H, Datta AN, Dill P, Schindler C, Fischer D: Increased incidence of Guillain-Barré syndrome after surgery. Eur J Neurol 19:1239-1244, 2012

5. Hadden RD, Cornblath DR, Hughes RA, Zielasek J, Hartung HP, Toyka KV, et al: Electrophysiological classification of Guillain-Barré syndrome: clinical associations and outcome. Plasma Exchange/Sandoglobulin Guillain-Barré Syndrome Trial Group. Ann Neurol 44: 780-788, 1998 
6. Hadden RD, Karch H, Hartung HP, Zielasek J, Weissbrich B, Schubert J, et al: Preceding infections, immune factors, and outcome in Guillain-Barré syndrome. Neurology 56:758-765, 2001

7. Huang SL, Qi HG, Liu JJ, Huang YJ, Xiang L: A rare complication of spine surgery: Guillain-Barré syndrome. World Neurosurg 84: 697-701, 2015

8. Jacobs BC, Rothbarth PH, van der Meché FG, Herbrink P, Schmitz PI, de Klerk MA, et al: The spectrum of antecedent infections in Guillain-Barré syndrome: a case-control study. Neurology 51:11101115, 1998

9. Landais AF: Rare neurologic complication of bariatric surgery: acute motor axonal neuropathy (AMAN), a severe motor axonal form of the Guillain Barré syndrome. Surg Obes Relat Dis 10:e8587, 2014

10. Lee CH, Song GS, Kim YH, Son DW, Lee SW: Spontaneous spinal epidural hematoma coexisting Guillan-Barré syndrome in a child: a case report. Korean J Spine 13:167-169, 2016

11. Li X, Xiao J, Ding Y, Xu J, Li C, He Y, et al: Clinical and electrophysiological features of post-traumatic Guillain-Barré syndrome. BMC Neurol 17:142, 2017

12. Rattananan W, Thaisetthawatkul P, Dyck PJ: Postsurgical inflammatory neuropathy: a report of five cases. J Neurol Sci 337:137140,2014
13. Rivas S, Douds GL, Ostdahl RH, Harbaugh KS: Fulminant GuillainBarré syndrome after closed head injury: a potentially reversible cause of an ominous examination. Case report. J Neurosurg 108: 595-600, 2008

14. Scozzafava J, Jickling G, Jhamandas JH, Jacka MJ: Guillain-Barré syndrome following thoracic spinal cord trauma. Can J Anaesth 55:441-446, 2008

15. Sejvar JJ, Kohl KS, Gidudu J, Amato A, Bakshi N, Baxter R, et al: Guillain-Barré syndrome and Fisher syndrome: case definitions and guidelines for collection, analysis, and presentation of immunization safety data. Vaccine 29:599-612, 2011

16. Sipilä JO, Soilu-Hänninen M: The incidence and triggers of adultonset Guillain-Barré syndrome in southwestern Finland 2004-2013. Eur J Neurol 22:292-298, 2015

17. Staff NP, Engelstad J, Klein CJ, Amrami KK, Spinner RJ, Dyck PJ, et al: Post-surgical inflammatory neuropathy. Brain 133:28662880, 2010

18. Tan IL, Ng T, Vucic S: Severe Guillain-Barré syndrome following head trauma. J Clin Neurosci 17:1452-1454, 2010

19. Wakerley BR, Yuki N. Infectious and noninfectious triggers in Guillain-Barré syndrome. Expert Rev Clin Immunol 9:627-639, 2013

20. Yuki N, Hartung HP: Guillain-Barré syndrome. N Engl J Med 366:2294-2304, 2012 